Speckle tracking echocardiography detects decreased cardiac longitudinal function in anthracycline-exposed survivors of childhood cancer

\title{
Ylanen, Kaisa
}

2016-10

Ylanen , K , Eerola , A , Vettenranta , K \& Poutanen , T 2016 , ' Speckle tracking echocardiography detects decreased cardiac longitudinal function in anthracycline-exposed survivors of childhood cancer ' , European journal of pediatrics , vol. 175 , no. 10 , pp. 1379-1386 . https://doi.org/10.1007/s00431-016-2776-9

http://hdl.handle.net/10138/228391

https://doi.org/10.1007/s00431-016-2776-9

publishedVersion

Downloaded from Helda, University of Helsinki institutional repository.

This is an electronic reprint of the original article.

This reprint may differ from the original in pagination and typographic detail.

Please cite the original version. 


\title{
Speckle tracking echocardiography detects decreased cardiac longitudinal function in anthracycline-exposed survivors of childhood cancer
}

\author{
Kaisa Ylänen $^{1,2}$ (D) Anneli Eerola ${ }^{1}$ - Kim Vettenranta ${ }^{3,4} \cdot$ Tuija Poutanen $^{1,2}$
}

Received: 22 November 2015 /Revised: 22 August 2016 /Accepted: 5 September 2016 /Published online: 13 September 2016

(C) Springer-Verlag Berlin Heidelberg 2016

\begin{abstract}
Longitudinal motion significantly contributes to the contraction of the ventricles. We studied the left (LV) and right ventricular (RV) longitudinal functions in 75 anthracycline-exposed, long-term childhood cancer survivors and 75 healthy controls with conventional echocardiography, tissue Doppler imaging (TDI), speckle tracking echocardiography (STE) of the mitral and tricuspid annular motion, and real-time three-dimensional echocardiography (RT-3DE). Cardiac magnetic resonance (CMR) imaging was performed on 61 of the survivors. The survivors had lower systolic myocardial velocities in the LV and lower diastolic velocities in both ventricles by TDI than did their healthy peers. The STE-based tissue motion annular
\end{abstract}

Communicated by Jaan Toelen

Electronic supplementary material The online version of this article (doi:10.1007/s00431-016-2776-9) contains supplementary material, which is available to authorized users.

Kaisa Ylänen

kaisa@ylanen.fi

Anneli Eerola

anneli.eerola@fimnet.fi

Kim Vettenranta

kim.vettenranta@hus.fi

Tuija Poutanen

tpoutanen@kolumbus.fi

1 Department of Pediatrics, Tampere University Hospital, PO BOX 2000, FIN-33521 Tampere, Finland

2 University of Tampere, Tampere, Finland

3 Hospital for Children and Adolescents, PO BOX 281, FIN-00029 HUS Helsinki, Finland

4 University of Helsinki, Helsinki, Finland displacement (TMAD) values describing the LV and RV systolic longitudinal function (MAD and TAD mid\%, respectively) were also lower among the survivors $(15.4 \pm 2.4$ vs. $16.1 \pm 2.2 \%$, $p=0.049$ and $22.5 \pm 3.0$ vs. $23.5 \pm 3.0 \%, p=0.035$ ). MAD and TAD mid in millimeters correlated with the respective ventricular volumes measured with RT-3DE or CMR.

Conclusion: Childhood cancer survivors exposed to low to moderate anthracycline doses had decreased longitudinal systolic and diastolic functions (TDI or STE) compared with healthy controls. The STE-based TMAD is a fast and reproducible method to assess cardiac longitudinal function.

What is Known?

- High anthracycline doses cause LV dysfunction as evidenced by a decreased ejection fraction.

What is new?

- Low to moderate anthracycline doses also have a negative impact on the $L V$ and $R V$ longitudinal systolic and diastolic function.

- TMAD is a new and fast method to assess the cardiac longitudinal function after anthracycline exposure.

Keywords Anthracycline $\cdot$ Child $\cdot$ Malignancy $\cdot$ Speckle tracking $\cdot$ Tissue Doppler imaging

$\begin{array}{ll}\text { Abbreviations } \\ \text { CMR } & \text { Cardiac magnetic resonance } \\ \text { EDV } & \text { End-diastolic volume } \\ \text { EF } & \text { Ejection fraction } \\ \text { ESV } & \text { End-systolic volume } \\ \text { LV } & \text { Left ventricle/ventricular } \\ \text { MAD } & \text { Mitral annular displacement } \\ \text { RT-3DE } & \text { Real-time three-dimensional echocardiography } \\ \text { RV } & \text { Right ventricle/ventricular } \\ \text { STE } & \text { Speckle tracking echocardiography }\end{array}$

Abbreviations

CMR Cardiac magnetic resonance

EDV End-diastolic volume

EF Ejection fraction

ESV End-systolic volume

LV Left ventricle/ventricular

MAD Mitral annular displacement

RT-3DE Real-time three-dimensional echocardiography

STE Speckle tracking echocardiography 
TAD Tricuspid annular displacement

TAPSE Tricuspid annular plane systolic excursion

TDI Tissue Doppler imaging

TMAD Tissue motion annular displacement

\section{Introduction}

Up to $16 \%$ of anthracycline-exposed childhood cancer survivors develop clinical heart failure [18]. Clinical symptoms and a decrease in the left ventricular (LV) ejection fraction (EF) are late signs of cardiotoxicity. The right ventricular (RV) function has not been at focus in the assessment of anthracycline-induced cardiotoxicity mostly due to limitations in the imaging methods.

The LV wall consists of subepicardial, predominantly lefthandedly and longitudinally oriented, mid-wall circumferential and subendocardial, mainly right-handedly and longitudinally oriented myofibers [27]. The concerted function of the circumferential and longitudinal myofiber layers contributes importantly to the overall LV ejection. In children, the longitudinal deformation has been proposed to play a greater role in the LV function with their less prominent circumferential layers [26]. The RV wall consists of superficial, mainly circumferentially arranged and deep, longitudinally oriented myofibers [11]. Due to the myofiber arrangement, longitudinal shortening contributes to the great proportion of the physiological RV contraction [4, 25].

Tricuspid annular plane systolic excursion (TAPSE) is an easily obtained, M-mode-based method for the evaluation of RV longitudinal function $[4,16]$, while tissue Doppler imaging (TDI) enables the measurement of myocardial velocities and thus both the systolic and diastolic functions [36]. Speckle tracking echocardiography (STE)-based tissue motion annular displacement (TMAD) is a novel, fast, and easy method to measure LV and RV longitudinal function and correlates well with cardiac magnetic resonance (CMR) imaging [1, 31]. Yet, data on the impact of anthracyclines on LV and RV longitudinal functions among children remain limited [6, 10, 13, 14, 28], and the use of the TMAD method has not been established among childhood cancer survivors.

Our aim was to characterize both LV and RV longitudinal functions by different echocardiographic methods and relate the results with volumetric real-time three-dimensional echocardiography (RT-3DE) and CMR data among anthracycline-exposed long-term childhood cancer survivors.

\section{Methods}

\section{Patients and controls}

We prospectively enrolled all consecutive long-term survivors of childhood cancer attending the population-based pediatric hematology-oncology service of Tampere University Hospital (Tampere, Finland) between February 2010 and June 2011, with anthracyclines as a part of their chemotherapy and having been off treatment for at least 5 years. Survivors with an active malignancy or congenital heart disease were excluded, but the four with a previously diagnosed anthracycline-induced cardiomyopathy were included. Of the initially recruited 86 patients, 76 agreed to participate, but 1 was excluded with a suboptimal acoustic window. The anthracycline dose conversion to doxorubicin isotoxic equivalents was performed according to the Children's Oncology Group recommendations (www. survivorshipguidelines.org).

Another 75 healthy children/adolescences were recruited as gender-, body surface area-, and age-matched controls. The key characteristics of the survivors and controls are presented in Table 1.

\section{Echocardiography}

Echocardiographic examination was performed with the iE33 ultrasound machine (Royal Philips Electronics, Philips Healthcare, Bothell, WA, USA) using an S8-3, S5-1, X3-1, or X5-1 transducer depending on patient size. The two-dimensional, Doppler, and M-mode examinations were performed from the standard subcostal, apical, and parasternal views. The transducer position was optimized to minimize angulation and avoid foreshortening. An electrocardiogram was recorded

Table 1 The key characteristics of the study patients

\begin{tabular}{|c|c|c|c|}
\hline Variable & $\begin{array}{l}\text { Patients } \\
(n=75)\end{array}$ & $\begin{array}{l}\text { Controls } \\
(n=75)\end{array}$ & $\begin{array}{l}p \\
\text { value }\end{array}$ \\
\hline Female & $41(55)$ & $41(55)$ & \\
\hline Male & $34(45)$ & $34(45)$ & \\
\hline Age (years) & $14.3 \pm 3.1$ & $14.2 \pm 3.2$ & 0.875 \\
\hline Height $(\mathrm{cm})$ & $159.5 \pm 15.6$ & $161.4 \pm 16.2$ & 0.004 \\
\hline Weight (kg) & $54.5 \pm 17.0$ & $53.7 \pm 16.0$ & 0.163 \\
\hline Body surface area $\left(\mathrm{m}^{2}\right)$ & $1.55 \pm 0.31$ & $1.55 \pm 0.30$ & 0.309 \\
\hline Acute lymphoblastic leukemia & $33(44)$ & & \\
\hline Acute myeloid leukemia & $9(12)$ & & \\
\hline Solid tumor & $33(44)$ & & \\
\hline Age at diagnosis ${ }^{\mathrm{a}}$ (years) & $3.8(2.0-6.7)$ & & \\
\hline $\begin{array}{l}\text { Time from end of primary } \\
\text { therapy }^{\mathrm{a}} \text { (years) }\end{array}$ & $\begin{array}{c}7.1(6.0- \\
10.0)\end{array}$ & & \\
\hline $\begin{array}{l}\text { Cumulative anthracyclines }{ }^{\mathrm{a}}(\mathrm{mg} / \\
\left.\mathrm{m}^{2}\right)\end{array}$ & $\begin{array}{l}223(163- \\
301)\end{array}$ & & \\
\hline Cardiac irradiation & $9(12)$ & & \\
\hline Relapsed disease & $6(8)$ & & \\
\hline $\begin{array}{l}\text { Allogeneic stem cell } \\
\text { transplantation }\end{array}$ & $7(9)$ & & \\
\hline
\end{tabular}

Values are $n(\%)$, mean $\pm \mathrm{SD}$ or median (interquartile range)

${ }^{a}$ Non-normalized distribution 
simultaneously. Three consecutive cardiac cycles were acquired and digitally stored. The average of the three cardiac cycles was used in all the echocardiographic analyses except in RT-3DE.

The transmitral and transtricuspid flow velocities were recorded by positioning the sample volume of the pulsedwave Doppler between the tips of the mitral/tricuspid leaflets in the apical four-chamber views. The peak velocities of the early filling (E) of the mitral and tricuspid inflows were measured.

Fractional shortening was derived from the M-mode image acquired from the parasternal long axis view according to the American Society of Echocardiography guidelines [19]. The TAPSE was measured from the apical four-chamber view [16]. The M-mode cursor was placed at the junction of the tricuspid valve annulus and free wall of the RV, and the total excursion of the base during systole was measured from one leading edge to the other.

The TDI was performed from the apical four-chamber view to obtain the longitudinal annular velocities with a pulsedwave Doppler mode. A sample volume of $4 \mathrm{~mm}$ was placed at the basal septal and lateral annulus of the mitral valve as well as the basal lateral annulus of the tricuspid valve [23]. A narrow angle sector was used to achieve a frame rate of at least $150 / \mathrm{s}$. The measurements from each of the myocardial wall segments included the peak velocity during early ventricular diastole $\left(\mathrm{E}^{\prime}\right)$ and systole $\left(\mathrm{S}^{\prime}\right)$.

The two-dimensional echocardiograms of the LV and RV from the apical four-chamber views were obtained for the STE-based TMAD imaging $[1,7]$. The data was analyzed offline using the QLAB software (Philips Q-lab, Version 9.0, 3DQA, Philips Healthcare, Bothell, WA, USA). For the LV, three points were placed in a diastolic frame: the basal septal, lateral mitral annulus, and apex. The software automatically tracked the two mitral valve annular points and calculated their absolute displacement toward the LV apex throughout the cardiac cycle. Displacement of the annular points (mitral annular displacement (MAD) septal and lateral), as well as that of the midpoint of the two (MAD mid), was expressed in millimeters (Fig. 1a). In order to normalize for the LV length, the total midpoint displacement was also expressed as a ratio of the longitudinal ventricle length at end-diastole (MAD mid\%). For the RV, another three points were placed at the septal and lateral tricuspid annulus and apex and the respective parameters (tricuspid annular displacement (TAD) septal, lateral, mid and mid\%) were obtained (Fig. 1b).

The RT-3DE was performed and the LV end-diastolic (EDV) and end-systolic volumes (ESV) and LVEF measured as previously described [35].

Two investigators (K.Y. and T.P.) independently measured 20 randomly selected datasets for the MAD and TAD mid interobserver and the former (K.Y.) a single set twice for intraobserver variability.

\section{Cardiac magnetic resonance imaging}

Sixty-one survivors also underwent CMR imaging and the LV EDV, ESV, and LVEF were measured from the short axis slices and the respective parameters for the RV (RV ESV, RV EDV, and RVEF) from the axial slices as described [34].

\section{Statistical analysis}

The IBM $^{\circledR}$ SPSS $^{\circledR}$ Statistics version 21 (IBM Corp., Armonk, NY, USA) software was used for the statistical analysis. Categorical data are presented as frequencies and percentages, normally distributed data as mean $\pm \mathrm{SD}$, and non-normally distributed data as median and interquartile range. The group means were compared between the survivors and the controls with the paired samples $t$ test. The independent samples $t$ test was used for the means among the survivors. The correlations were assessed with the Pearson's correlation coefficients for normally distributed data and the Spearman's rho test in the case of non-normality. All tests were two-sided and $p$ values $<0.05$ were considered significant. The intraobserver and interobserver variations were assessed using the Bland Altman analysis [3].

\section{Results}

Four survivors were on medication for a previously diagnosed anthracycline-induced cardiomyopathy at the time of analysis. Six pairs were excluded from the TAPSE and one from LV septal TDI analysis due to missing images. Four pairs had their LV images unanalyzable for the TMAD analysis due to inadequate image quality.

The Bland Altman plots for the interobserver and intraobserver variabilities for MAD and TAD mid are presented in Fig. 2 (Online Resource 1).

\section{Left ventricle}

The echocardiographic data on the survivors and controls are presented in Table 2. The former had a lower fractional shortening and RT-3DE-derived LVEF.

Again, the survivors had lower systolic LV myocardial velocities $\left(\mathrm{S}^{\prime}\right)$. The early diastolic myocardial velocities $\left(\mathrm{E}^{\prime}\right)$ in the LV septal walls were also lower compared with those of the controls. Transmitral to septal mitral annular early diastolic velocity ratios $\left(\mathrm{E} / \mathrm{E}^{\prime}\right)$ were higher among the survivors.

The mitral annular midpoint longitudinal displacement (MAD mid) and MAD mid\% were lower among the survivors. The lower normal limit for MAD mid\% derived from the -2 SD of our healthy controls was $11.8 \%$. An abnormal MAD mid\% was thus detected in 3 of the 71 
Fig. 1 The four-chamber apical views used for the tracking of mitral (a) and tricuspid annular displacement (b). The points selected for LV (A) are the septal and lateral annulus of the mitral valve and LV apex and for the RV (b) the septal and lateral annulus of the tricuspid valve and RV apex. Arrows indicate the annular midpoints. The two curves represent displacement of the septal and lateral points of the valve annulus during the cardiac cycle. The color kinesis shows mitral/tricuspid annulus displacement
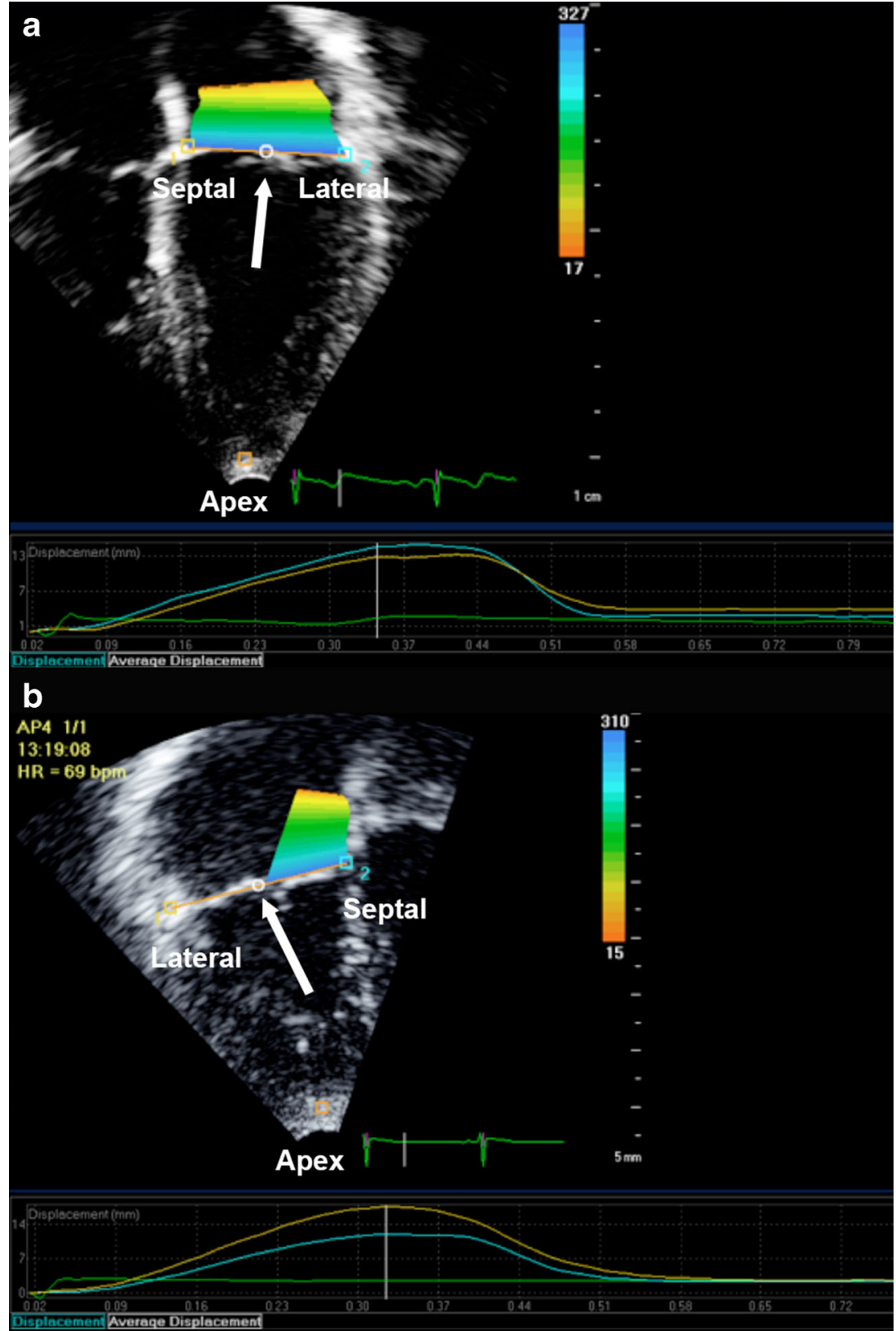

(4\%) survivors with 2 also having a CMR-derived LVEF of $<50 \%$ ( 1 had no CMR performed). None of the three had a prior diagnosis of an anthracycline-induced cardiomyopathy. The survivors with an RT-3DE-derived LVEF of $<50 \%$ had a lower MAD mid\% than did those with LVEF $\geq 50 \%(13.8 \pm 2.0$ vs. $15.6 \pm 2.3 \%, p=0.026$, respectively). The MAD mid\% was also lower among those with a CMR-derived LVEF of $<50 \%(15.0 \pm 2.4$ vs. $16.3 \pm 2.2 \%, p=0.028$, respectively).

When comparing those exposed or unexposed to cardiac irradiation, the former $(n=9)$ had a lower MAD mid\% than the latter $(13.8 \pm 1.8$ vs. $15.6 \pm 2.3 \%, p=0.031$, respectively) or their matched controls $(16.2 \pm 2.1 \%, p=0.002)$.

\section{Right ventricle}

TAPSE did not differ between the groups, and all survivors had it above $-2 \mathrm{SD}(16.8 \mathrm{~mm})$ of the healthy controls.

The systolic myocardial RV velocities did not differ between the two groups. Yet, the early diastolic myocardial velocities $\left(E^{\prime}\right)$ in the RV lateral walls were lower, and the transtricuspid to tricuspid annular early diastolic velocity ratios $\left(E / E^{\prime}\right)$ were higher among the survivors.

The tricuspid annular midpoint longitudinal displacement (TAD mid) and TAD mid\% were, again lower among the survivors. The lower normal limit for the latter derived from the $-2 \mathrm{SD}$ of our healthy controls was $17.6 \%$. An abnormal 
Table 2 The echocardiographic parameters

\begin{tabular}{|c|c|c|c|c|}
\hline Variable & Number & Patients & Controls & $p$ value \\
\hline \multicolumn{5}{|l|}{ Left ventricle } \\
\hline \multicolumn{5}{|l|}{ Doppler } \\
\hline $\begin{array}{l}\text { Mitral E velocity } \\
(\mathrm{cm} / \mathrm{s})\end{array}$ & 74 & $91.6 \pm 14.6$ & $93.8 \pm 15.3$ & 0.355 \\
\hline \multicolumn{5}{|l|}{ M-mode } \\
\hline LV FS (\%) & 75 & $32.9 \pm 3.1$ & $34.9 \pm 3.2$ & $<0.001$ \\
\hline \multicolumn{5}{|l|}{ RT-3DE } \\
\hline LVEF $(\%)$ & 75 & $56.2 \pm 6.4$ & $59.4 \pm 4.2$ & $<0.001$ \\
\hline \multicolumn{5}{|l|}{ TDI } \\
\hline $\mathrm{E}^{\prime}$ lateral LV $(\mathrm{cm} / \mathrm{s})$ & 75 & $17.9 \pm 3.0$ & $18.7 \pm 3.3$ & 0.087 \\
\hline $\mathrm{S}^{\prime}$ lateral LV $(\mathrm{cm} / \mathrm{s})$ & 75 & $10.2 \pm 1.7$ & $10.9 \pm 2.0$ & 0.016 \\
\hline $\mathrm{E}^{\prime}$ septal LV $(\mathrm{cm} / \mathrm{s})$ & 74 & $12.2 \pm 1.7$ & $13.5 \pm 1.6$ & $<0.001$ \\
\hline $\mathrm{S}^{\prime}$ septal LV $(\mathrm{cm} / \mathrm{s})$ & 74 & $7.4 \pm 1.0$ & $7.8 \pm 0.8$ & 0.004 \\
\hline LV E/E' septal & 73 & $7.6 \pm 1.4$ & $7.0 \pm 1.2$ & 0.003 \\
\hline \multicolumn{5}{|l|}{ STE } \\
\hline MAD lateral (mm) & 71 & $12.1 \pm 2.7$ & $13.0 \pm 2.4$ & 0.022 \\
\hline MAD septal (mm) & 71 & $11.9 \pm 2.1$ & $12.5 \pm 1.9$ & 0.082 \\
\hline MAD mid (mm) & 71 & $12.7 \pm 2.3$ & $13.6 \pm 2.0$ & 0.006 \\
\hline MAD mid (\%) & 71 & $15.4 \pm 2.4$ & $16.1 \pm 2.2$ & 0.049 \\
\hline \multicolumn{5}{|l|}{ Right ventricle } \\
\hline \multicolumn{5}{|l|}{ Doppler } \\
\hline $\begin{array}{l}\text { Tricuspidal E } \\
\text { velocity }(\mathrm{cm} / \mathrm{s})\end{array}$ & 72 & $61.4 \pm 10.5$ & $61.3 \pm 10.2$ & 0.979 \\
\hline \multicolumn{5}{|l|}{ M-mode } \\
\hline TAPSE $(\mathrm{mm})$ & 69 & $22.7 \pm 3.3$ & $23.9 \pm 3.6$ & 0.065 \\
\hline \multicolumn{5}{|l|}{ TDI } \\
\hline $\mathrm{E}^{\prime}$ lateral RV $(\mathrm{cm} / \mathrm{s})$ & 75 & $14.4 \pm 2.5$ & $15.9 \pm 3.1$ & 0.005 \\
\hline $\mathrm{S}^{\prime}$ lateral RV $(\mathrm{cm} / \mathrm{s})$ & 75 & $13.8 \pm 1.7$ & $14.2 \pm 2.6$ & 0.227 \\
\hline $\mathrm{RV}$ E/E' lateral & 72 & $4.4 \pm 1.1$ & $4.0 \pm 0.8$ & 0.011 \\
\hline \multicolumn{5}{|l|}{ STE } \\
\hline TAD lateral (mm) & 75 & $19.8 \pm 3.5$ & $20.7 \pm 3.7$ & 0.104 \\
\hline TAD septal (mm) & 75 & $13.0 \pm 2.2$ & $14.0 \pm 1.9$ & 0.004 \\
\hline TAD mid (mm) & 75 & $16.9 \pm 2.6$ & $18.1 \pm 2.6$ & 0.005 \\
\hline TAD mid (\%) & 75 & $22.5 \pm 3.0$ & $23.5 \pm 3.0$ & 0.035 \\
\hline
\end{tabular}

$E F$ ejection fraction, $F S$ fractional shortening, $L V$ left ventricular, $M A D$ mitral annular displacement, $R T-3 D E$ real-time three-dimensional echocardiography, STE speckle tracking echocardiography, TAD tricuspid annular displacement, TAPSE tricuspid annular plane systolic excursion, $T D I$ tissue Doppler imaging

TAD mid\% was detected in 4 of the $75(5 \%)$ survivors and all of them had their CMR-derived RVEF of $<55 \%$ and 1 a prior diagnosis of anthracycline-induced cardiomyopathy. The TAD mid\% did not differ between those unexposed or exposed to irradiation $(22.5 \pm 3.1$ vs. $22.0 \pm 2.4 \%, p=0.660$, respectively). Yet, those unexposed to irradiation $(n=66)$ had a lower TAD mid\% than did their control counterparts $(22.5 \pm 3.1$ vs. $23.8 \pm 3.0 \%, p=0.022$, respectively). Eight with a cumulative anthracycline dose of $\geq 350 \mathrm{mg} / \mathrm{m}^{2}$ had a lower TAD mid\% than did those with lower doses ( $20.5 \pm 2.7 \%$ vs. $22.7 \pm 3.0 \%, p=0.048$, respectively).

\section{Correlations}

Left ventricle

The MAD mid correlated with the RT-3DE-derived LV volumes (EDV: $r=0.54$, ESV: $r=0.42$, stroke volume $r=0.56$, $p<0.001$ for all) and with the CMR-derived LV volumes (EDV: $r=0.46$, ESV $r=0.43$, and stroke volume: $r=0.41$, $p=0.001$ for all). The LVEF (RT-3DE and CMR) did not correlate with the MAD mid\% $(r=0.26, p=0.03$ and $r=0.10, p=0.451$, respectively).

\section{Right ventricle}

The TAD mid showed only a modest correlation with the CMR-derived RV EDV $(r=0.38, p=0.002)$, ESV $(r=0.33, p=0.009)$, or stroke volume $(r=0.35, p=0.006)$. The TAD mid\% did not correlate with the CMR-derived $\operatorname{RVEF}(r=0.19, p=0.145)$. The TAPSE correlated with the TAD mid $\%$ only modestly $(r=0.30, p=0.008)$.

\section{Discussion}

Modern cancer therapy still renders a negative impact on the cardiac function. We demonstrate the anthracycline-exposed survivors of childhood cancer to have a statistically significant decrease in their longitudinal systolic and diastolic ventricular function compared with their matched healthy controls, even in the absence of exposure to markedly higher, historical anthracycline doses. For studying the mitral and tricuspid valve annular motions and velocities, both the TDI and STE methods were employed. The EFs were assessed with the three-dimensional imaging methods (RT-3DE and CMR) being more accurate and reproducible than the two-dimensional echocardiography was [20]. The survivors with an abnormal LVEF by RT-3DE and CMR had a depressed longitudinal motion upon comparison with those with a normal LVEF. The impairment in the LV longitudinal systolic function was most obvious among those also exposed to cardiac irradiation.

\section{Tissue motion annular displacement}

The STE-based TMAD is a novel method for assessing longitudinal cardiac function [7]. Its advantages include angleindependency, two-dimensionality, the time required, and the possibility to be performed even with a reduced echocardiographic image quality $[5,33]$. To our knowledge, this is the first study to document an abnormal longitudinal LV and RV function with the TMAD among childhood cancer survivors. 
Our measurements of the mitral annular midpoint displacement (MAD mid) correlated with the LV volumes obtained by the three-dimensional volumetric methods, RT-3DE and CMR. In a few, mainly adult cohorts, the TMAD parameters have been demonstrated to correlate with the LVEF assessed by a two-dimensional echocardiography (biplane method) $[5$, 7, 33], RT-3DE [5] and CMR [2, 31, 33], but this was not demonstrable in our pediatric cohort.

According to our results, the LV longitudinal function seems to be vulnerable to cardiac irradiation. This is in accordance with the subendocardial longitudinal myofibers being particularly susceptible to toxic impacts [12, 29, 33].

The volumes and EFs of the RV are difficult to measure due to its complex anatomy. CMR is the best method for visualization, but it requires anesthesia in children less than 8 to 10 years of age. The TMAD is a useful method in assessing the RV function among children with its limited imaging time. These parameters (TAD septal, lateral and mid\%) have been found to correlate with CMR-derived RVEF among adults [1]. To our knowledge, the RV TMAD has not been assessed in children.

The TMAD parameters of the RV (TAD mid and mid\%) representing the global longitudinal function were lower among our survivors. Yet, the TAPSE and TDI of the RV measuring regional displacement and velocities failed to show a decline in the longitudinal function. Thus, we conclude that the LV partly contributes to the RV longitudinal function through the interventricular septum with the longitudinal function of RV lateral wall staying within the normal range despite a decline in the global longitudinal function [11]. The correlations between the tricuspid annular displacement (TAD mid) and CMR-derived RV volumes were weaker than those for the $\mathrm{LV}$, possibly reflecting the more complex anatomy of RV.

The length of the heart varies with the age and size of children. The displacement ratio (MAD and TAD mid\%) normalizes the displacement in relation to the length of the ventricles, making the comparison of the parameters easier between individuals. However, the longitudinal function remains age-dependent [21], but pediatric reference values for the MAD or TAD mid\% remain unavailable. In the present study, gender-, body surface area-, and age-matched healthy controls were employed.

We solely used the four-chamber view for the TMAD analysis. Previous studies on LV have been performed with the two- and/or four-chamber views and seem to give comparable values $[2,5,7,29,31]$.

\section{Tricuspid annular plane systolic excursion}

The TAPSE in an easy method to assess the RV regional longitudinal function and is employable both for adults [32] and children [16]. It measures the longitudinal function only in one direction and is angle-dependent. Abnormally low values have been documented among children with the tetralogy of Fallot years after corrective operation [15]. Yet, normal values have been reported in children with an RV volume overload due to an atrial septum defect [15], emphasizing that TAPSE does not cover the RV function in toto.

The TAPSE has not been studied among pediatric cancer patients. One study among adult breast cancer patients showed a decline during chemotherapy [30]. All of our survivors had normal values and those for our healthy controls were in line with those previously published [16].

\section{Tissue Doppler imaging}

Our anthracycline-exposed survivors had decreased systolic myocardial velocities at the LV septal and lateral walls and decreased early diastolic myocardial velocities at the LV septal wall. The RV TDI values were normal in systole but abnormal in diastole. These results are in agreement with previous data on anthracycline-exposed children with a decreased LV systolic function with [14, 28] or without $[6,10] \mathrm{RV}$ diastolic dysfunction. Another study in childhood cancer survivors did not find abnormalities in the longitudinal ventricular function [13].

A transmitral early diastolic velocity/TDI mitral annular early diastolic velocity (E/E') value of $\geq 15$ has predicted rehospitalization and cardiac mortality among adults with congestive heart failure [8] and an increased mean LV diastolic pressure [24]. We show increased LV E/E' septal and RV E/E' lateral ratios among our patients. Unfortunately, we currently do not have established cutoff values for the pediatric TDI parameters able to detect those with abnormal systolic or diastolic function. TDI remains optimal in a serial assessment of the same patient with the same ultrasound system [17].

An advantage of TDI is the possibility to assess the systolic and diastolic function of both ventricles. A decreased $\mathrm{E}^{\prime}$ is an early marker for diastolic dysfunction usually preceding systolic dysfunction [22].

Myocardial tissue velocities decrease from the base to the apex and are higher at the lateral mitral and tricuspid annulus than in the interventricular septum [9]. Being age- and somewhat load-dependent, the pediatric TDI velocities remain highly variable. Myocardial velocities can be measured by two different TDI methods: the pulsed-wave values have been shown to be constantly higher and more comparable between two ultrasound systems than were those derived from the color TDI [17]. Thus, it is important to use method- and age-appropriate reference values. The TDI values of our healthy controls are in line with previously published pediatric reference values [9].

\section{Study limitations}

We were unable to assess the impact of the mildly impaired longitudinal cardiac function on exercise tolerance or the 
global longitudinal (only four-chamber view) and circumferential strain with STE of our survivors. Yet, the lack of established pediatric reference values for TMAD could be overcome through the use of matched controls.

\section{Conclusion}

Anthracycline-exposed childhood cancer survivors treated in 1993-2006 continue to have an impaired LV and RV longitudinal function both in systole and diastole, despite being subjected to a progressively less cardiotoxic treatment. As the multidimensional motion of the myocardium should be taken into account in the evaluation of the cardiac function, both STE and TDI constitute an optimal supplement to conventional M-mode. With the TMAD analysis being fast to perform and documented to have a low intraobserver and interobserver variability, we advocate its use as part of the imaging armamentarium in the evaluation of both the LV and RV function among childhood cancer survivors. Due to an age- and gender-specific variation in key measurements, ageappropriate reference values remain to be of key importance for the introduction of novel imaging methods into pediatric use.

Acknowledgments The authors warmly thank Satu Ranta, RN, for the practical assistance during the project.

This work was financially supported by the following sources: the Blood Disease Research Foundation, Helsinki; the Competitive Research Funding of the Tampere University Hospital (9L114 and 9N084), Tampere; the EVO funds of the Tampere University Hospital, Tampere; the Emil Aaltonen Foundation, Tampere; the Finnish Association of Hematology, Helsinki; the Finnish Cancer Foundation, Helsinki; the Finnish Cultural Foundation, Helsinki; the Finnish Cultural Foundation Pirkanmaa Regional Fund, Ylöjärvi; the Finnish Medical Foundation, Helsinki; the Foundation for Pediatric Research, Helsinki; the National Graduate School of Clinical Investigations, Helsinki; the Päivikki and Sakari Sohlberg Foundation, Helsinki; the Scientific Foundation of the City of Tampere, Tampere; and the Väre Foundation for Pediatric Cancer, Helsinki. The funding sources were in no way involved in the design or conduct of the study or writing of the article.

Compliance with ethical standards All procedures performed in studies involving human participants were in accordance with the ethical standards set by the institutional research committee and with the 1964 Helsinki Declaration and its later amendments or comparable ethical standards. Informed consent was obtained from all individual participants (and/or their legal guardians). No animal data were included.

Conflict of interest The authors declare that they have no conflicts of interest.

Authors' contributions Study concept and design: All authors.

Provision of study materials and patients: Kaisa Ylänen.

Collection and assembly of data: Kaisa Ylänen.

Data analysis and interpretation: All authors.

Manuscript writing: All authors.

Final approval of manuscript: All authors

\section{References}

1. Ahmad H, Mor-Avi V, Lang RM, Nesser HJ, Weinert L, Tsang W, Steringer-Mascherbauer R, Niel J, Salgo IS, Sugeng L (2012) Assessment of right ventricular function using echocardiographic speckle tracking of the tricuspid annular motion: comparison with cardiac magnetic resonance. Echocardiography 29:19-24

2. Black D, Bryant J, Peebles C, Godfrey K, Hanson M, Vettukattil J (2013) Tissue motion annular displacement of the mitral valve using two-dimensional speckle tracking echocardiography predicts the left ventricular ejection fraction in normal children. Cardiol Young 27:1-9

3. Bland JM, Altman DG (1986) Statistical methods for assessing agreement between two methods of clinical measurement. Lancet $1: 307-310$

4. Brown SB, Raina A, Katz D, Szerlip M, Wiegers SE, Forfia PR (2011) Longitudinal shortening accounts for the majority of right ventricular contraction and improves after pulmonary vasodilator therapy in normal subjects and patients with pulmonary arterial hypertension. Chest 140:27-33

5. Buss SJ, Mereles D, Emami M, Korosoglou G, Riffel JH, Bertel D, Schonland SO, Hegenbart U, Katus HA, Hardt SE (2012) Rapid assessment of longitudinal systolic left ventricular function using speckle tracking of the mitral annulus. Clin Res Cardiol 101:273280

6. Cheung YF, Hong WJ, Chan GC, Wong SJ, Ha SY (2010) Left ventricular myocardial deformation and mechanical dyssynchrony in children with normal ventricular shortening fraction after anthracycline therapy. Heart 96:1137-1141

7. DeCara JM, Toledo E, Salgo IS, Lammertin G, Weinert L, Lang RM (2005) Evaluation of left ventricular systolic function using automated angle-independent motion tracking of mitral annular displacement. J Am Soc Echocardiogr 18:1266-1269

8. Dokainish H, Zoghbi WA, Lakkis NM, Ambriz E, Patel R, Quinones MA, Nagueh SF (2005) Incremental predictive power of B-type natriuretic peptide and tissue Doppler echocardiography in the prognosis of patients with congestive heart failure. J Am Coll Cardiol 45:1223-1226

9. Eidem BW, McMahon CJ, Cohen RR, Wu J, Finkelshteyn I, Kovalchin JP, Ayres NA, Bezold LI, O'Brian Smith E, Pignatelli RH (2004) Impact of cardiac growth on Doppler tissue imaging velocities: a study in healthy children. J Am Soc Echocardiogr 17:212-221

10. Ganame J, Claus P, Uyttebroeck A, Renard M, D'hooge J, Bijnens B, Sutherland GR, Eyskens B, Mertens L (2007) Myocardial dysfunction late after low-dose anthracycline treatment in asymptomatic pediatric patients. J Am Soc Echocardiogr 20:1351-1358

11. Haddad F, Hunt SA, Rosenthal DN, Murphy DJ (2008) Right ventricular function in cardiovascular disease, part I: anatomy, physiology, aging, and functional assessment of the right ventricle. Circulation 117:1436-1448

12. Henein MY, Gibson DG (1999) Long axis function in disease. Heart 81:229-231

13. Kapusta L, Thijssen JM, Groot-Loonen J, Antonius T, Mulder J, Daniels O (2000) Tissue Doppler imaging in detection of myocardial dysfunction in survivors of childhood cancer treated with anthracyclines. Ultrasound Med Biol 26:1099-1108

14. Kocabas A, Kardelen F, Ertug H, Aldemir-Kocabas B, Tosun O, Yesilipek A, Hazar V, Akcurin G (2014) Assessment of early-onset chronic progressive anthracycline cardiotoxicity in children: different response patterns of right and left ventricles. Pediatr Cardiol 35: 82-88

15. Koestenberger M, Nagel B, Ravekes W, Everett AD, Stueger HP, Heinzl B, Sorantin E, Cvirn G, Gamillscheg A (2011) Tricuspid annular plane systolic excursion and right ventricular ejection 
fraction in pediatric and adolescent patients with tetralogy of Fallot, patients with atrial septal defect, and age-matched normal subjects. Clin Res Cardiol 100:67-75

16. Koestenberger M, Ravekes W, Everett AD, Stueger HP, Heinzl B, Gamillscheg A, Cvirn G, Boysen A, Fandl A, Nagel B (2009) Right ventricular function in infants, children and adolescents: reference values of the tricuspid annular plane systolic excursion (TAPSE) in 640 healthy patients and calculation of $\mathrm{z}$ score values. J Am Soc Echocardiogr 22:715-719

17. Koopman LP, Slorach C, Manlhiot C, McCrindle BW, Friedberg MK, Mertens L, Jaeggi ET (2010) Myocardial tissue Doppler velocity imaging in children: comparative study between two ultrasound systems. J Am Soc Echocardiogr 23:929-937

18. Kremer LC, van Dalen EC, Offringa M, Voute PA (2002) Frequency and risk factors of anthracycline-induced clinical heart failure in children: a systematic review. Ann Oncol 13:503-512

19. Lang RM, Bierig M, Devereux RB, Flachskampf FA, Foster E, Pellikka PA, Picard MH, Roman MJ, Seward J, Shanewise JS, Solomon SD, Spencer KT, Sutton MS, Stewart WJ, Chamber Quantification Writing G, American Society of Echocardiography's Guidelines and Standards, Committee, European Association of E (2005) Recommendations for chamber quantification: a report from the American Society of Echocardiography's guidelines and standards committee and the chamber quantification writing group, developed in conjunction with the European Association of Echocardiography, a branch of the European Society of Cardiology. J Am Soc Echocardiogr 18: $1440-1463$

20. Lu X, Xie M, Tomberlin D, Klas B, Nadvoretskiy V, Ayres N, Towbin J, Ge S (2008) How accurately, reproducibly, and efficiently can we measure left ventricular indices using M-mode, 2-dimensional, and 3-dimensional echocardiography in children? Am Heart J 155:946-953

21. Marcus KA, Mavinkurve-Groothuis AM, Barends M, van Dijk A, Feuth T, de Korte C, Kapusta L (2011) Reference values for myocardial two-dimensional strain echocardiography in a healthy pediatric and young adult cohort. J Am Soc Echocardiogr 24:625-636

22. Mertens L, Ganame J, Claus P, Goemans N, Thijs D, Eyskens B, Van Laere D, Bijnens B, D'hooge J, Sutherland GR, Buyse G (2008) Early regional myocardial dysfunction in young patients with Duchenne muscular dystrophy. J Am Soc Echocardiogr 21: 1049-1054

23. Mor-Avi V, Lang RM, Badano LP, Belohlavek M, Cardim NM, Derumeaux G, Galderisi M, Marwick T, Nagueh SF, Sengupta PP, Sicari R, Smiseth OA, Smulevitz B, Takeuchi M, Thomas JD, Vannan M, Voigt JU, Zamorano JL (2011) Current and evolving echocardiographic techniques for the quantitative evaluation of cardiac mechanics: ASE/EAE consensus statement on methodology and indications endorsed by the Japanese Society of Echocardiography. J Am Soc Echocardiogr 24:277-313

24. Ommen SR, Nishimura RA, Appleton CP, Miller FA, Oh JK, Redfield MM, Tajik AJ (2000) Clinical utility of Doppler echocardiography and tissue Doppler imaging in the estimation of left ventricular filling pressures: a comparative simultaneous Doppler-catheterization study. Circulation 102:1788-1794

25. Petitjean C, Rougon N, Cluzel P (2005) Assessment of myocardial function: a review of quantification methods and results using tagged MRI. J Cardiovasc Magn Reson 7:501-516

26. Sanchez-Quintana D, Garcia-Martinez V, Climent V, Hurle JM (1995) Morphological changes in the normal pattern of ventricular myoarchitecture in the developing human heart. Anat Rec 243: 483-495

27. Sengupta PP, Korinek J, Belohlavek M, Narula J, Vannan MA, Jahangir A, Khandheria BK (2006) Left ventricular structure and function: basic science for cardiac imaging. J Am Coll Cardiol 48: 1988-2001

28. Stapleton GE, Stapleton SL, Martinez A, Ayres NA, Kovalchin JP, Bezold LI, Pignatelli R, Eidem BW (2007) Evaluation of longitudinal ventricular function with tissue Doppler echocardiography in children treated with anthracyclines. J Am Soc Echocardiogr 20: 492-497

29. Suzuki K, Akashi YJ, Mizukoshi K, Kou S, Takai M, Izumo M, Hayashi A, Ohtaki E, Nobuoka S, Miyake F (2012) Relationship between left ventricular ejection fraction and mitral annular displacement derived by speckle tracking echocardiography in patients with different heart diseases. J Cardiol 60:55-60

30. Tanindi A, Demirci U, Tacoy G, Buyukberber S, Alsancak Y, Coskun U, Yalcin R, Benekli M (2011) Assessment of right ventricular functions during cancer chemotherapy. Eur J Echocardiogr 12:834-840

31. Tsang W, Ahmad H, Patel AR, Sugeng L, Salgo IS, Weinert L, Mor-Avi V, Lang RM (2010) Rapid estimation of left ventricular function using echocardiographic speckle-tracking of mitral annular displacement. J Am Soc Echocardiogr 23:511-515

32. Van De Bruaene A, De Meester P, Voigt JU, Delcroix M, Pasquet A, De Backer J, De Pauw M, Naeije R, Vachiery JL, Paelinck B, Morissens M, Budts W (2012) Right ventricular function in patients with Eisenmenger syndrome. Am J Cardiol 109:1206-1211

33. Xu J, Peng Y, Li C, Zhang J, Zhou C, Huang L, Xia C, Tang H, Rao L (2011) Feasibility of assessing cardiac systolic function using longitudinal fractional shortening calculated by two-dimensional speckle tracking echocardiography. Echocardiography 28:402-407

34. Ylänen K, Poutanen T, Savikurki-Heikkilä P, Rinta-Kiikka I, Eerola A, Vettenranta K (2013) Cardiac magnetic resonance imaging in the evaluation of the late effects of anthracyclines among long-term survivors of childhood cancer. J Am Coll Cardiol 61:1539-1547

35. Ylänen K, Eerola A, Vettenranta K, Poutanen T (2014) Threedimensional echocardiography and cardiac magnetic resonance imaging in the screening of long-term survivors of childhood cancer after cardiotoxic therapy. Am J Cardiol 113:1886-1892

36. Yu CM, Sanderson JE, Marwick TH, Oh JK (2007) Tissue Doppler imaging a new prognosticator for cardiovascular diseases. J Am Coll Cardiol 49:1903-1914 